\title{
Estimation of stress change in ductile part of the crust inferred from seismic scattering
}

\author{
Kyosuke OKAMOTO $^{1}$, Hitoshi MIKADA ${ }^{1}$ Tada-nori GOTO ${ }^{1}$ and Junichi TAKEKAWA ${ }^{1}$ \\ ${ }^{1}$ Dept. of Civil and Earth Res. Eng., Kyoto University
}

\begin{abstract}
In the past, stress field in the subsurface has been measured by various techniques. For example, borehole-breakout, stress release method, hydraulic fracturing, strain gauge buried in the ground are used to measure the stress field after costly drilling the subsurface. Beside the techniques requiring direct access to the subsurface, the stress field is also measured indirectly. Electro Distance Meter, Global Positioning System, etc. are used to measure a surface deformation in time. From the surface deformation, stress change in the subsurface is estimated. However the estimated stress change in the subsurface is largely affected by inhomogeneities located near the surface, landslide, slope failure, etc. Thus, stress field in the subsurface can be obtained directly and indirectly although some problems described above are still remaining. Here we focus on seismic scattering wave, particularly coda- $Q$ value, to measure a stress field change in the subsurface. Coda- $Q$, which is derived from the attenuation of coda envelope, is perceived to be an indicator of the inhomogeneity in the subsurface. In this study, we hypothesize that coda- $Q$ indicates stress change in a deep subsurface since coda- $Q$ is obtained from seismic waves traveling over a wide range of the crust including ductile part of the crust. Numerically it has been revealed that coda- $Q$ indicates the magnitude of the stress change in the deep subsurface, while the surface strain distribution is largely affected by inhomogeneities located near the surface. In this study we confirm that coda- $Q$ indicates stress change in the deep subsurface using real field data that was acquired at the time of the Iwate-Miyagi Nairiku earthquake in 2008. The stress change estimated from coda- $Q$ corresponds with that in the ductile part calculated by a fault model, which is acquired by a seismic wave analysis, whereas the estimated stress change dose not correspond with that from GPS measurement. It means that coda- $Q$ could indicate stress change in the deep subsurface more accurate than GPS measurement.
\end{abstract}

\section{INTRODUCTION}

Estimation of the variation of magnitude and orientation of stress field in the deep subsurface is important for various scientific and engineering fields, e.g., to understand time-variant seismicity, to drill safely and efficiently during resource exploitation and tunnel construction, etc. So far, in-situ stress field has been measured using borehole breakout, hydraulic fracturing, various core-based methods, etc. However it is difficult to measure the stress field in the deep subsurface due to the cost of deep drilling, limitations in equipment and in the spatial coverage of observation. On the other hand, stress change in the subsurface is estimated indirectly. Surface deformation is obtained using Global Positioning System (GPS) observation, and stress change in the subsurface is estimated from the surface deformation. However we know that the observation could strongly be disturbed by inhomogeneities in the subsurface and that the estimated strain may not always reflects real in-situ stress changes. The response of in-situ stress field could also be examined using seismic waves travelling through the subsurface material. For example, we know that the anisotropy of shear wave phase velocity attributes to the orientation of cracks in the crustal material that stems from regional stress field (Crampin, 1985). The difference in the phase velocity of shear waves causes shear wave to split into fast and slow shear waves of the same propagation direction and the orientation and density of cracks in the subsurface could be estimated. The orientation and density of cracks have connection with stress field, so that, stress field could be estimated. However the shear wave phase velocity is also affected by the effects of geological structure such as joints, sedimentary rock, etc. (Nishizawa, 2005).

Seismic scattering reflects inhomogeneities of the crust (Aki and Chouet, 1975), and the properties of the inhomogeneities could also be influenced by the change in the stress field (Okamoto et al., 2013). Coda wave is formed by the superposition of scattered seismic waves and coda- $Q\left(Q_{c}\right)$ value has been found correlated with the seismicity (Jin and Aki, 1988).

In this study, we hypothesize that $Q_{c}^{-1}$ could 
indicate stress field in the subsurface, several or several dozens $\mathrm{km}$ depth, without the effects of inhomogeneities located in the subsurface, while the surface strain observed by GPS may be influenced by the inhomogeneities. We employ data that was acquired at the time of the Iwate-Miyagi Nairiku earthquake in 2008, and verify our hypothesis in the real data.

\section{RELATIONSHIP BETWEEN $Q_{c}^{-1}$ AND STRESS CHANGE}

$Q_{c}^{-1}$ is obtained from attenuation ratio of a seismic coda wave. Eq. 1 is fitted to the envelope of a coda wave, then $Q_{c}^{-1}$ is estimated.

$$
e(t)=A_{0} t^{-n} \exp \left(-\frac{\omega}{2 Q_{c}} t\right)
$$

where $A_{0}$ is a constant, $t$ represents the time from origin of an earthquake and $\omega$ is angular frequency. The term of $t^{-n}$ represents geometrical spreading. Power $n$ is from 1 to 2 depending on the dominance wave in practice. However in this study we set $n=$ 0 because we assume that incident wave is a plane wave coming from below a station.

Okamoto et al. (2014) numerically revealed a relationship between $Q_{c}^{-1}$ and stress change using a crustal model (Eq. 2).

$$
y=A[1-\exp (B x)]+C
$$

where $y$ and $x$ are stress change and $Q_{c}^{-1}$ respectively, and $A, B$ and $C$ are constants. We estimate the constants by a grid search; $A=61.79$, $B=-1.71$ and $C=-6.02$ for the model of $V_{p}=$ $5300 \mathrm{~m} / \mathrm{s}, V_{s}=3060 \mathrm{~m} / \mathrm{s}$ and $\rho=2200 \mathrm{~kg} / \mathrm{m}^{3} . Q_{c}^{-1}$ increases as the magnitude of stress loaded to the crust increases.

\section{CASE STUDIES (IWATE-MIYAGI NAIRIKU EARTHQUAKE IN 2008)}

We confirm that $Q_{c}^{-1}$ could reflect the real stress change in the subsurface even under the existence of local inhomogeneities located in the subsurface using real data. We take an example to estimate the temporal variation in $Q_{c}^{-1}$ before and after the Iwate-Miyagi Nairiku earthquake in 2008 (Jun. 14, $M_{w} 6.9$, depth $8 \mathrm{~km}$ ) using earthquakes records from a dense earthquake monitoring station network in Japan called Hi-net (Okada et al., 2004). The period of observation is chosen as two years before and after the earthquake. We have selected earthquakes whose magnitudes range from 1.5 to 7.0. The frequency of $6 \mathrm{~Hz}$ is used to estimate $Q_{c}^{-1}$. Seismic events of epicentral distance to every station less than $40 \mathrm{~km}$ are extracted from the
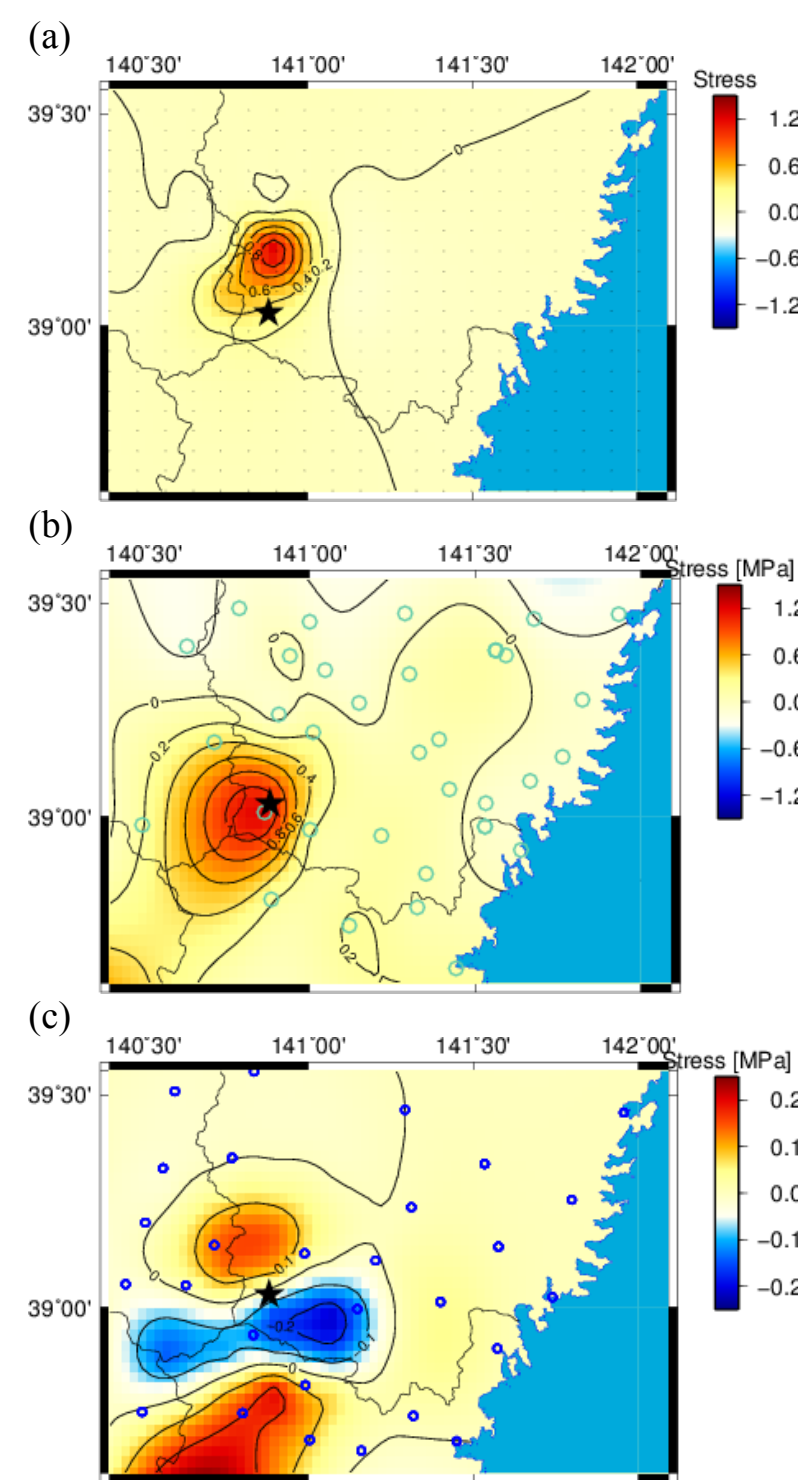

Figure 1 (a) Estimated stress change by the theoretical strain calculated from the dislocation model. The star shows epicenter. (b) Estimated stress change from $Q_{c}^{-1}$. The star shows epicenter and the circles show Hi-net stations. (c) Estimated stress change from the surface strain observed by geodetic GPS measurement. The star shows epicenter and the circles show GEONET stations.

earthquake archive of the Hi-net.

Iwate-Miyagi Nairiku earthquake in 2008 occurred on Jan. 14, 2008 in Japan. Figs. 1a, b and c show changes in the magnitude of the stress inferred from the theoretical strain summed up for depths from 15 to $50 \mathrm{~km}$, the variation in $Q_{c}^{-1}$ for earthquakes located for $20-100 \mathrm{~km}$ depth, and the surface deformation observed by GPS measurement associated with the Iwate-Miyagi Nairiku earthquake. The depth of $15 \mathrm{~km}$ corresponds with that of the Conrad discontinuity and the depth of 
$50 \mathrm{~km}$ corresponds with that of the Moho discontinuity (Katsumata, 2010). The theoretical stress change is calculated by the theoretical equation (Okada, 1992) using a fault model from the teleseismic analysis. The variation in $Q_{c}^{-1}$ is converted to that in the magnitude of the stress (Fig. 1b) using Eq.2. Using the theoretical equation, the stress change summed up for depths from 15 to $50 \mathrm{~km}$ (Fig. 1c) is obtained from the surface deformation.

It is found that the stress change inferred from the theoretical strain and $Q_{c}^{-1}$ show a similar tendency to each other. Both the stress and $Q_{c}^{-1}$ increase circularly around the epicentre. On the other hand, the stress change inferred from the surface deformation shows bimodal or much more complicated distribution. This is probably due to inhomogeneities located in the subsurface that perturb the surface deformation distribution. Our results could imply that $Q_{c}^{-1}$ shows stress change in the subsurface, whose depth is several or several dozen $\mathrm{km}$ without the effects of inhomogeneities located in the subsurface. We found that $Q_{c}^{-1}$ indicated that stress increased around the hypocenter of the target earthquake. The $Q_{c}^{-1}$ is affected by stress change in a deep subsurface like the ductile part of the crust, whose depth is around $15-50 \mathrm{~km}$ depth.

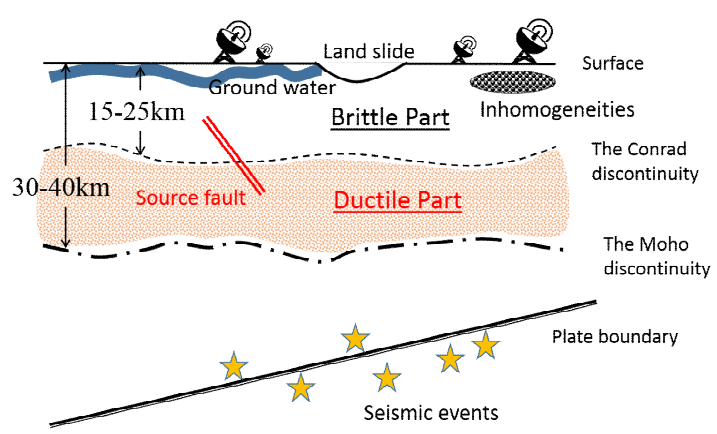

Figure 2 Aki (2004) pointed out that uncertainty of fracturing in the brittle part of the crust covers deterministic behavior toward stress change in the ductile part.

Iio et al. (2004) followed the brittle-ductile hypothesis (Aki, 2004) and pointed out that stress concentration takes place beneath an earthquake fault in the lower crust, after an intraplate earthquake at the fault has occurred. The increase in the estimated stresses in the deep subsurface (Figs. $2 \mathrm{a}$ and $\mathrm{b}$ ) could be explained by the hypothesis. Sugaya et al. (2009) estimated that $Q_{c}^{-1}$ has a relationship with change in a state of cracks in the ductile part. Our result indicates that the stress change in the ductile part of the crust agrees with their discussion.

\section{CONCLUSION}

It is indicated that $Q_{c}^{-1}$ could be used to estimate regional scale stress accumulation without local and shallow disturbances. When the surface deformation is utilized to see the stress accumulation in the subsurface, we confirmed that the distribution of stress changes in the subsurface may differ from that obtained from earthquake mechanism probably due to local inhomogeneties in the elastic parameters of crustal materials in the subsurface. On the other hand, we confirmed that the stress distribution estimated from $Q_{c}^{-1}$ show consistent results to earthquake mechanisms using a regional damaging earthquake. We would like to conclude that $Q_{c}^{-1}$ could be a powerful tool to monitor the stress change in the deep subsurface. Also, our method might be applied for the other geophysical measurements such as for oilfield development, geotechnical construction, etc.

ACKNOWLEDGMENT: We thank Japan Society for the Promotion of Science (JSPS) for the Grant-in-Aid for JSPS Fellows (24•373) for supporting the present research. We also thank National Research Institute for Earth Science and Disaster Prevention (NIED) and Geospatial Information Authority of Japan (GSI) to make their data available.

\section{REFERENCES}

1) Aki, K., 2004, A new view of earthquake and volcano precursors, Earth Planets Space, 56, 689-713

2) Aki, K. and Chouet, B., 1975, Origin of Coda Waves: Source, Attenuation, and Scattering Effects, J. Geophys. Res., 80, 3322-3342.

3) Crampin, S., 1985, Evaluation of anisotropy by shear-wave splitting, Geophysics, 50, 142-152.

4) Iio, Y., Sagiya, T., and Kobayashi, Y., 2004, What controls the occurrence of shallow intraplate earthquakes?, Earth Planets Space, 56, 1077-1086.

5) Jin, A., and Aki, K., 1988, Spatial and temporal correlation between coda $Q$ and seismicity in China, Bull. Seism. Soc. Am., 78, 741-769.

6) Katsumata, A., 2010, Depth of the Moho discontinuity beneath the Japanese islands estimated by traveltime analysis, J. Geophys. Res., 115, B04303

7) Nishizawa, O., 2005, Seismic wave velocities in rocls: I: Modeling heterogeneous media and their elastic wave velocities, J. Geography, 114, 921-948.

8) Okada, Y., 1992, Internal deformation due to 
shear and tensile faults in a half-space, Seism. Soc. Am., 82, 1018-1040.

9) Okada, Y., Kasahara, K., Hori, S., Obara, K., Sekiguchi, S., Fujiwara, H., and Yamamoto, A., 2004, Recent progress of seismic observation networks in Japan -Hi-net, F-net, K-NET and KiK-net -, Earth Planets and Space, 56, $\mathrm{xV}-\mathrm{xviii}$.

10) Okamoto, K., Mikada, H., Goto, T-N, and Takekawa, J., 2013, Numerical analysis of the relationship between time-variant coda- $Q$ and the variation in crustal stress, Geophys. J. Int., $195,575-581$

11) Okamoto, K., Mikada, H., Goto, T-N, and Takekawa, J., 2014, Estimation of spatiotemporal stress variation in subsurface inferred from seismic scattering, 2nd International KAUST-KACST-JCCP Workshop on Surface and Subsurface 4D Monitoring.

12) Sugaya, K., Hiramatsu, Y., Furumoto, M., and Katao, H., 2009, Coseismic change and recovery of scattering environment in the crust after the 1995 Hyogo-ken Nanbu Earthquake, Japan, Bull. Seism. Soc. Am., 99, 435-440. 